\title{
Trauma and Triage: Applying the Dick and Carey Instructional Design Model to a Primary Survey Clinical Workshop
}

\author{
Maxwell J. Jabaay ${ }^{1}$, Leah O. Grcevich ${ }^{1}$, Dario A. Marotta ${ }^{1,2}$, Joseph H. Reynolds ${ }^{3}$ \\ 1. Department of Research, Alabama College of Osteopathic Medicine, Dothan, USA 2. Department of Neurology, \\ Division of Neuropsychology, University of Alabama, Birmingham, USA 3. Department of Leadership and Professional \\ Studies, Troy University, Montgomery, USA
}

Corresponding author: Maxwell J. Jabaay, jabaaymj@acom.edu

\begin{abstract}
Instructional design in the setting of medical education can be challenging. Multiple instructional design methods exist and have been documented in the literature. However, detailed applications of these models in the context of medical education are underreported. This technical report describes the application of a specific instructional design model to an acute care curriculum. Specifically, we illustrate the Dick and Carey instructional design model used at a one-day clinical workshop aimed at improving medical student exposure to the primary survey.
\end{abstract}

Categories: Medical Education, Quality Improvement, Trauma

Keywords: instructional design, primary survey, trauma, curriculum development and evaluation

\section{Introduction}

The primary survey (PS) is a rapid and systematic approach to evaluating critically ill or injured patients that focuses on airway, breathing, circulation, disability, and exposure (ABCDE) management [1]. This approach optimizes care team communication and efficiency while prioritizing threats to life and reducing adverse patient outcomes [2]. As such, the PS has become a core competency in undergraduate and graduate medical education [3]. Successfully performing a PS in a high-stress and rapidly evolving trauma situation is challenging for many students [4-5]. Efforts have been made to increase student exposure to trauma management in the clinical phase of medical education. However, the life-threatening nature of clinical encounters that require a primary survey has inherent risk. In many cases, the role of the primary surveyor is assumed by senior clinicians, further limiting student involvement and experience [6-7]. Thus, we set out to design a curriculum to help medical students gain proficiency and confidence in the primary survey using an instructional design technique known as the Dick and Carey model.

Received 05/22/2020 Review began 06/03/2020 Review ended 06/06/2020 Published 06/16/2020

\section{() Copyright 2020} Jabaay et al. This is an open access article distributed under the terms of the Creative Commons Attribution License CC-BY 4.0., which permits unrestricted use, distribution, and reproduction in any medium, provided the original author and source are credited.
The Dick and Carey model is considered one of the foremost Analysis, Design, Development, Implementation, and Evaluation (ADDIE) models, popular in industry, business, and academic environments. Since its first introduction in 1968, the model has been updated several times and is now described in detail in the 8th edition of Dick, Carey, and Carey's The Systematic Design of Instruction [8]. The Dick and Carey model has been successfully applied to medical curricula in the past, thus we elected to use this model as the roadmap for our instructional design [9-10]. Realistic medical simulation has shown to improve medical student performance-based assessments in the management of simulated trauma; therefore, simulation served as the framework by which we delivered our curriculum [4, 11]. In this technical report, we document design considerations, learning objectives, and assessments for a reproducible preclinical trauma workshop known as Trauma and Triage.

\section{Technical Report}

This technical report illustrates the Dick and Carey model by applying it to a preclinical trauma curriculum [8]. Even with the development of seemingly similar curricula, it is important to apply these methods and adapt a curriculum based on specific learners and context. The Dick and Carey Model progresses through a series of steps and allows for continuous revision throughout the process. Figure 1 graphically represents the steps of the model. 


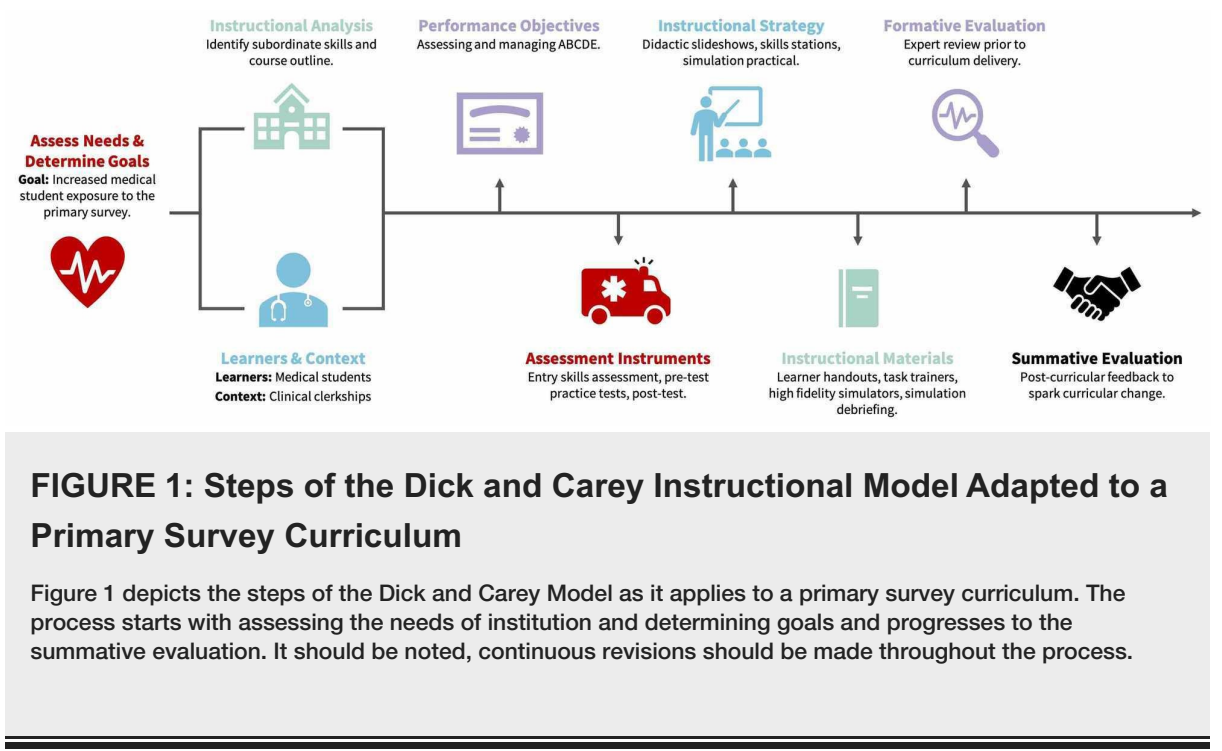

\section{Step 1: Assess needs and determine goals}

The application of the Dick and Carey model begins by establishing whether or not a performance-based problem exists and whether or not the problem can be solved through additional education. Only then can the instructional design team continue with a needs assessment. A needs assessment identifies the desired performance level and compares it to current performance. This performance gap acts as a path to guide further curriculum development. We recommend reviewing the literature for existing curricula that may have addressed similar needs. This can streamline efforts and generate additional ideas to incorporate in your final design. Finally, it is important to develop instructional goals to help guide the design process.

For example, we identified an inherent gap in acute care management in a cohort of medical students. An informal interview revealed students felt they had learned technical skills, such as basic life support (BLS) and advanced cardiac life support (ACLS); however, they had yet to utilize the PS to determine whether these skills would apply in a rapidly evolving trauma situation. While this did not elucidate a quantitative performance deficit, it illustrated a working example of a gap in clinical knowledge that could benefit from instruction. A literature review revealed similar concerns at other medical institutions without evidence of established acute care curricula [4-5]. Following our needs assessment, we set out to achieve our instructional goal of creating a curriculum to improve preclinical exposure to the primary survey through education aimed at managing a patient's airway, breathing, circulation, disability, and exposure.

\section{Step 2: Analyze learners and context}

The next step has two distinct aspects: (1) analyzing the learners, and (2) considering the future environment where these skills would be performed (herein referred to as the context) [8]. For instance, we identified first- and second-year medical students with varying levels of simulation and medical experience as learners. These students desired to improve proficiency in the PS, a skill used frequently in the context of inpatient medical school rotations.

\section{Steps 3 and 4: Instructional analysis and performance objectives}

The third and fourth steps of the Dick and Carey model involve an instructional analysis to design the layout of the curriculum in order to achieve the instructional goals [8]. The composition of the instructional analysis involves translating instructional goals into actionable performance objectives consisting of three unique components: condition statement, behavior statement, and a criteria statement [8].

A condition statement establishes the environment in which a scenario will take place. This gives the learner context in terms of preceding or triggering events and available resources. Condition statements can be manipulated by instructors to increase or decrease complexity based on the preceding analysis of learner experience [8].

The behavior statement describes the actions learners must take to achieve an objective [8, 12]. Behavior statements should be specific and actionable to avoid ambiguity. For instance, verbs that should be avoided include: "know," "understand," and "appreciate" because they lack specificity [8, 12].

A criteria statement sets performance expectations for how a learner's performance will be graded or judged in future assessments.

A detailed set of performance objectives helps to streamline assessment creation and reduce tangential 
instructional material. To illustrate this, Figure 2 provides a color-coded example of one of the 10 performance objectives created for our instructional goal related to airway management. Conditional statements are colored in orange, behavioral statements are colored in blue, and criteria statements are colored in black. We recommend using this syntax for performance objective creation as it streamlines productivity and ensures each performance objective contains the proper components. A complete list of performance objectives used in the development of Trauma and Triage is provided in appendix 1.

\section{2.) In the resuscitation bay, manage the patient's compromised airway by performing (condition):}

a. a simple airway intervention like head-tilt/chin-lift, a jaw thrust or suctioning (behavior). Learner should open or clear the patient's airway. If this does not work, the learner should move to an advanced intervention (criteria).

b. an advanced intervention by inserting a basic airway device such as an oropharyngeal or nasopharyngeal airway (behavior). Learner should be able to correctly place the basic airway device on an airway task trainer. If this does not work, the learner should move to a definitive intervention (criteria).

c. a definitive airway intervention by sedating and then placing an endotracheal (ET) tube (behavior). Learner should be able to verbalize an appropriate sedative, correctly place the ET tube on an airway task trainer, confirm placement by chest radiograph and chest wall motion (criteria).

\section{FIGURE 2: Example of a Performance Objective for Airway Management}

Finally, for each performance objective, subordinate or prerequisite skills must be identified. A subordinate skill is a foundational skill required for a learner to successfully achieve a performance objective. As an illustration, Figure 3 depicts examples of subordinate skill flow-charts for performance objectives of the Trauma and Triage curriculum. In the example of airway management, a subordinate tree begins with the most basic required skills (such as verbalizing the indications for airway intervention) and progresses to more advanced psychomotor skills (such as performing intubation on a task trainer).

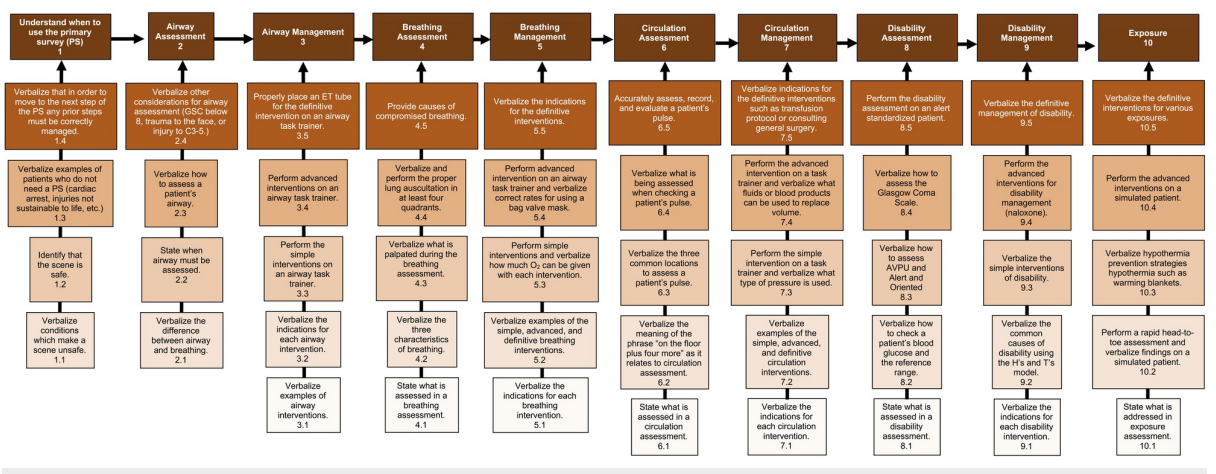

\section{FIGURE 3: Subordinate Skill Flowchart for Primary Objectives}

Subordinate skill flow-charts must be made for each primary objective with more basic introductory skills at the bottom transitioning to more advanced skills above.

\section{Step 5: Assessment instruments}

Once performance objectives are established, various assessments are required to evaluate whether or not a learner has accomplished a specific performance objective. These assessments include an entry skills test, pre-test, practice tests, and post-tests [8].

Entry skills tests are intended to screen learners for the foundational knowledge required to be successful in a particular program. Learners who do not possess a minimum competency should be referred for remediation prior to enrolling in the curriculum.

Pre-tests are pre-curricular assessments which gauge a group's foundational proficiency with the educational material. Pre-tests are different from entry-skills tests in that they are not used to evaluate a minimum level of competency. Instead, they identify strengths and weaknesses in the group's knowledge related to course material. In doing so, this allows instructors to tailor curriculum design toward a group of participants and maximize potential educational outcomes [8]. On a practical level, questions used to assess entry-skills are often combined with pre-test questions and evaluated differently based on answer selection.

Practice tests are intracurricular evaluations that provide learners with instant performance feedback for a particular skill or objective. For a learner, practice tests function as a learning tool. For instructors, practice tests identify content areas which could use additional reinforcement or clarification. In either situation, practice tests allow both instructors and learners an opportunity to correct performance before the final 


\section{Cureus}

post-test evaluation.

Post-tests are the final evaluations used to determine whether performance objectives have been met. Posttests should reflect the type of objective being evaluated. For instance, technical skills should be evaluated with practicums, while verbal skills should be evaluated with oral inquisitions.

In the setting of Trauma and Triage, entry skills tests and pre-tests were combined into a single evaluation and are provided as a reference in appendix 2 . Multiple choice questions and answers were used for the evaluation. Incorrect multiple-choice questions will be used to modify the group's curriculum. Excessive incorrect responses flagged potential learners for remediation. Five practice-tests were developed to be used during the curriculum and are provided as a reference in appendix 3. Two simulated acute care scenarios were used as post-tests to demonstrate proficiency with the PS and are outlined in Figure 4.

\section{Scenario Overview}

\section{Scenario 1}

A professional roofer falls from roof causing a $\mathrm{C} 2$ fracture and traumatic brain injury (TBI) as well as a pneumothorax and open femur fracture

\section{Scenario 2}

Confused septic patient wanders into roadway and is hit by a car leading to open book pelvis fracture

\section{Intervention Performance Objectives}

\section{Airway-normal assessment}

2. Breathing-patient has decreased breath sounds on one side $\rightarrow$ needle aspiration indicated for a tension pneumothorax (PO 4a 4c)

3. Circulation-patient has signs and symptoms of hypotensive shock and a profusely bleeding extremity injury $\rightarrow$ control bleeding by packing or applying tourniquet and initiate volume resuscitation (PO $6 \mathrm{a}$ or $6 \mathrm{~b}$ )

4. Disability-patient is becoming progressively more confused $\rightarrow$ a head $\mathrm{CT}$ is indicated (PO 8c)

5. Exposure-remove patient's clothing identifying an open fracture and profuse bleeding $\rightarrow$ hemorrhage control and surgical consultation are required (PO 6a, 6c and 10c)
1. Airway-assessment is initially normal $\rightarrow$ decompensating patient indicates need for intubation (PO 2a, 2b, 2c)

2. Breathing-normal assessment

3. Circulation-patient has signs of distributive and hemorrhagic shock without an external source of bleeding $\rightarrow$ begin volume resuscitation (PO $6 \mathrm{~b}$, $6 c)$

4. Disability-patient is confused as a result of a medical condition (sepsis)

5. Exposure-remove patient's clothing to identify a partially healed wound, and assessment of pelvis reveals signs of a pelvic fracture $\rightarrow$ stabilize pelvis with binder (PO 10b, 10c)

\section{FIGURE 4: Simulation Scenarios Derived from POs}

Figure 4 references performance objectives (POs). Every case requires the performance of each assessment PO (PO 1, 3, 5, 7, 9), however, management steps (PO 2, 4, 6, 8, 10) are determined based on the specific findings in each simulation.

\section{Step 6: Instructional strategy}

After producing curricular evaluations, performance objectives are used to establish instructional strategies, which should align with teaching modalities. For instance, didactic modules can be used for objectives related to memorizing facts, while task-based learning should be used for application or psychomotorrelated objectives. Once teaching modalities have been selected for each performance objective, logical considerations can be addressed, such as reserving a location, procuring equipment, and identifying qualified instructors. For example, Trauma and Triage utilized low fidelity task-trainers to teach methods of assessing patients during the PS, while didactic sessions were reserved for discussing potential causes of disability through gross pathology slides and radiographic imaging.

\section{Step 7: Instructional materials}


After developing an instructional strategy, the next step is to determine which instructional materials best suit the educational purpose. Instructional materials can include self-made slideshows, note packets, and worksheets. We recommend considering materials that balance short-term and long-term retention. For instance, while slideshows and interactive media are more engaging as a short-term learning tool, note packets and workbooks provide students with a lasting reference to use in the future. Trauma and Triage used a combination of materials including slideshow presentations, printed workbooks, and open-source literature [1]. Since simulations were used in the course, consolidated versions of the performance objectives were reviewed with participants following simulation exercises. A well-structured debrief is critical for student learning and has been shown to significantly improve learning outcomes compared to those who did not receive debriefing [13].

\section{Step 8: Formative evaluation of instruction}

The progress thus far constitutes a preliminary curriculum. An independent review by a subject matter expert, known as a formative evaluation, establishes the potential for the curriculum to accomplish the instructional goals. The formative evaluation serves to improve the effectiveness of the course [8]. In the case of Trauma and Triage, we consulted several board-certified emergency physicians and medical education experts. By doing so, we improved the quality of the course by applying feedback. Through this review, we also established that the instructional design had the potential to achieve our instructional goals.

\section{Step 9: Summative evaluation}

The final step of the Dick and Carey instructional design model calls for a summative evaluation. After the completion of the curriculum, it is necessary to solicit post-hoc feedback. This may come in the form of personal interviews, group interviews, or questionnaires. Surveys can be administered as written documents or in an on-line format. In the case of Trauma and Triage, we elected to conduct one-on-one personal interviews. Personal interviews gave us the latitude of expanding on learner feedback to further improve the curriculum.

\section{Discussion}

The Analysis, Design, Development, Implementation, and Evaluation (ADDIE) model has been cited as an instructional design element in the medical education literature [10-11]. However, little detail has been provided on how these models were applied. Further, the literature lacks a detailed technical report documenting the application of such a model in the context of medical education. Thus, our goal was to mend this gap in the literature and provide medical educators with a framework with which to approach similar curricular designs.

Instructional design can be an arduous and overwhelming process. Even a relatively short curriculum, such as Trauma and Triage, requires considerable planning and effort to successfully achieve educational objectives. The Dick and Carey instructional design model can be applied to a variety of goal-directed simulation curricula [10-11]. We recommend this model as it ensures that proper learning objectives have been identified, that assessment tools highlight those learning objectives, and that the curriculum and its outcomes are valuable for the learner.

\section{Conclusions}

The Dick and Carey instructional design model is a systematic approach to curriculum development. In this technical report, we document the application of the Dick and Carey model to a one-day primary survey workshop. Here we demonstrate the ease of applying the Dick and Carey model in the setting of medical education, thereby serving as a suitable method for designing a curriculum even for the most novice instructional designer.

\section{Appendices}

\section{Appendix 1}




\section{Cureus}
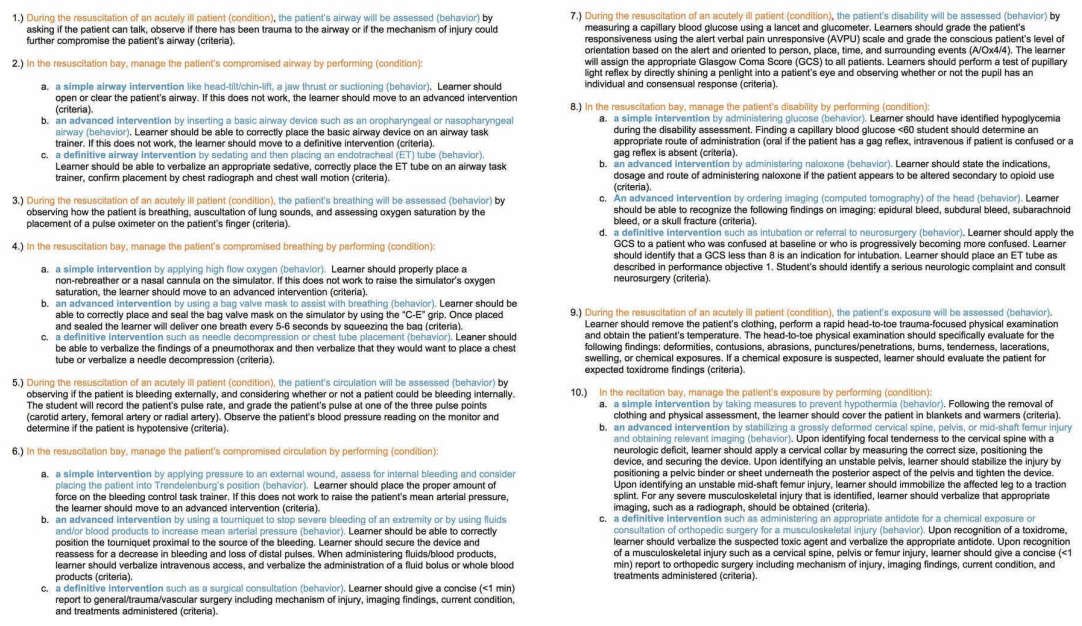

10.) $\ln _{\text {a. }}$

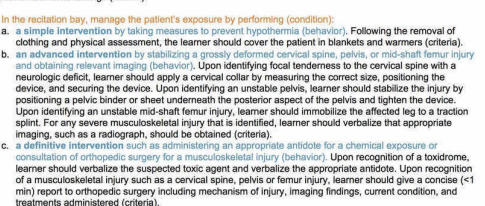

FIGURE 5: Primary Objectives for Primary Survey Curriculum

\section{Appendix 2}

\section{Combined Entry Skills and Pre-Curricular Evaluation}

1. What patients should you use the ABCDE approach for your initial assessment? a. Critically ill patients

b. Stable patients

d. All patients

2. You are in Walmart when you hear a loud thud and then a panicked person in the next aisle over You rush over and find an elderly man lying on the floor and he is not moving. What is the first thing you should do?
a. Assess the patient's airway
b. Begin CPR
c. Ensure the scene is safe
d. Remove the patients clothing

3. You are on call for your general surgery rotation and your team has been activated for a trauma call. A 30 y/o male is brought to the ER by EMS after being shot 2 times in the abdomen. You are tasked with performing a primary survey. What is the easiest way to assess the airway in this trauma patient?

a. A cap refill test

b. Preform a head-tilt and chin-lift

c. Ask the patient's name

d. Instruct the patient to show you three fingers on his right hand

e. Sternal rub and see if the patient pushes you away

4. A $45 \mathrm{y} / 0$ female is brought into the trauma bay by EMS after she was an unrestrained passenger in motor vehicle accident. On primary survey you find that the patient has decreased breathing and has suffered severe jaw trauma. The patient will need rescue breaths and suction. By performing these two interventions what aspects of the primary survey are you addressing?

a. Rescue breath = Airway and Suction = Breathing

a. Rescue breath $=$ Airway and Suction $=$ Breathing
b. Rescue breath $=$ Airway and Suction $=$ Airway

b. Rescue breath $=$ Airway and Suction $=$ Airway
c. Rescue breath $=$ Breathing and Suction $=$ Breathing

c. Rescue breath $=$ Breathing and Suction $=$ Airway

5. A patient was stabbed with a knife and bleeding is controlled. The patient has lost nearly 1 liter of blood. The patient's blood pressure is $88 / 62 \mathrm{mmHg}$ and he/she has a heart rate of 147 BPM. What is the next best step for this patient?

a. Intubate the patient

b. Start the patient on an infusion on Norepi

c. Give fluids or blood products

d. Reassurance

6. What does AVPU stand for?

7. You are interviewing a $50 \mathrm{y} / \mathrm{o}$ male patient on the medical surgical floor. You notice that the patient becomes unresponsive. You feel for a pulse and it is not present. A code blue is activated and you begin CPR. What compression rate should be used to deliver the highest quality CPR?

a. $80-100$

b. $100-120$

c. $120-140$

d. As fast as you can

Answers: 1.D; 2.C; 3.C; 4.D; 5.C; 6.Alert,Verbal, Painful, Unresponsive; 7.B 


\section{Appendix 3}
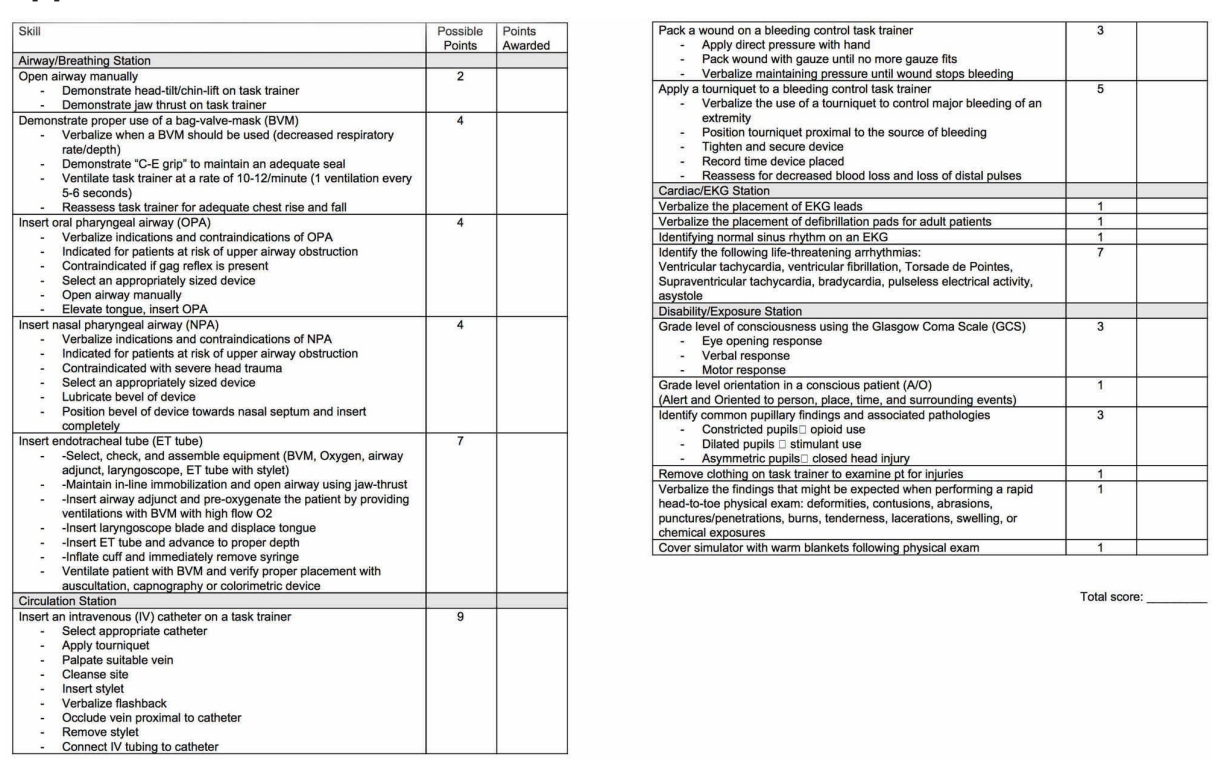

Total score:

FIGURE 7: Practice Tests

\section{Additional Information}

\section{Disclosures}

Human subjects: All authors have confirmed that this study did not involve human participants or tissue. Animal subjects: All authors have confirmed that this study did not involve animal subjects or tissue. Conflicts of interest: In compliance with the ICMJE uniform disclosure form, all authors declare the following: Payment/services info: All authors have declared that no financial support was received from any organization for the submitted work. Financial relationships: All authors have declared that they have no financial relationships at present or within the previous three years with any organizations that might have an interest in the submitted work. Other relationships: All authors have declared that there are no other relationships or activities that could appear to have influenced the submitted work.

\section{References}

1. Thim T, Krarup NH, Grove EL, Rohde CV, Løfgren B: Initial assessment and treatment with the Airway, Breathing, Circulation, Disability, Exposure (ABCDE) approach. Int J Gen Med. 2012, 5:117-121. 10.2147/IJGM.S28478

2. Smith D, Bowden T: Using the ABCDE approach to assess the deteriorating patient. Nurs Stand. 2017, 32:5163. 10.7748/ns.2017.e11030

3. Englander R, Flynn T, Call S, et al.: Toward defining the foundation of the MD degree: core entrustable professional activities for entering residency. Acad Med. 2016, 91:1352-1358. 10.1097/ACM.0000000000001204

4. Ruesseler M, Weinlich M, Muller MP, Byhahn C, Marzi I, Walcher F: Simulation training improves ability to manage medical emergencies. Emerg Med J. 2010, 27:734-738. 10.1136/emj.2009.074518

5. Gala PK, Osterhoudt K, Myers SR, Colella M, Donoghue A: Performance in trauma resuscitation at an urban tertiary level I pediatric trauma center. Pediatr Emerg Care. 2016, 32:756-762. 10.1097/PEC.0000000000000942

6. Shaban S, Cevik AA, Canakci ME, Kuas C, El Zubeir M, Abu-Zidan F: Do senior medical students meet recommended emergency medicine curricula requirements?. BMC Med Educ. 2018, 18:8. 10.1186/s12909017-1110-1

7. Hammond J: Simulation in critical care and trauma education and training . Curr Opin Crit Care. 2004, 10:325-329. 10.1097/01.ccx.0000140950.47361.c9

8. Dick W, Carey L, Carey JO: The Systematic Design of Instruction. Pearson Education, Boston; 2015.

9. Hsu TC, Lee-Hsieh J, Turton MA, Cheng SF: Using the ADDIE model to develop online continuing education courses on caring for nurses in Taiwan. J Contin Educ Nurs. 2014, 45:124-131. 10.3928/00220124-2014021904

10. Reinbold S: Using the ADDIE model in designing library instruction. Med Ref Serv Q. 2013, 32:244-256. 10.1080/02763869.2013.806859

11. Ali J, Adam RU, Sammy I, Ali E, Williams JI: The simulated Trauma Patient Teaching Module--does it 


\section{Cureus}

improve student performance?. J Trauma. 2007, 62:1416-1420. 10.1097/TA.0b013e3180479813

12. Gagné RM, Wager WW, Golas KC, Keller JM: Principles of Instructional Design . Wadsworth Thomson Learning, Belmont; 2005.

13. Savoldelli GL, Naik VN, Park J, Joo HS, Chow R, Hamstra SJ: Value of debriefing during simulated crisis management: oral versus video-assisted oral feedback. Anesthesiology. 2006, 105:279-285.

10.1097/00000542-200608000-00010 